\title{
Pengaruh Promosi Dan Harga Terhadap Keputusan Pembelian Pada PT. Wahana Chemindo Jaya Medan
}

\author{
Eva Margareth Sarah ${ }^{1}$, Wennita Tumanggor ${ }^{2}$ \\ ${ }^{12}$ Program Studi Manajemen Universitas Sari Mutiara indonesia \\ 1 evasarah.1989@gmail.com, ${ }^{2}$ wennitatumanggor@gmail.com
}

\begin{abstract}
The studi aims to determine whether promotions and prices have a significant effect on purchasing decisions at PT. Wahana Chemindo Jaya Medan. Where the consumers from PT. Wahana Chemindo Jaya Medan. The population in this study were all customers of PT. Wahana Chemindo Jaya Medan. The sample taken was 65 respondent using a non probability sampling technique. The data analysis method used is quantitative metdhod and data analysis method consisting of normality test, and heteroscedasticity test, multiple linaer regression terst, hypothesis testing consisting of $t$ test and $f$ test and coefficient od determination test (R2). Working on data analysis methods using the help os SPSS 25 For windows. This study concludes that the promotion and price variabel have a positive and significant impact on purchasing decions at PT. Wahana Chemindo Jaya Medan. This result can be seen based on the coefficient of determination test which produces an $R$ square value of 0,787. This shows that promotions and prices are able to influence the purchasing decisions of customers of PT. Wahana Chemindo Jay Medan by $78,7 \%$.
\end{abstract}

Keywords: Promotion; Price; Purchase Decision

\begin{abstract}
Abstrak
Penelitian ini bertujuan untuk mengetahui apakah promosi dan harga berpengaruh signifikan terhadap keputusan pembelian pada PT. Wahana Chemindo Jaya Medan, dimana yang menjadi konsumennya adalah pelanggan dari PT. Wahana Chemindo Jaya Medan. Populasi dalam penelitian ini adalah seluruh pelangan PT. Wahana Chemindo Jaya Medan, sampel yang diambil sebanyak 65 responden dengan menggunakan Teknik non probability sampling. Metode analisis data yang digunakan adalah metode kuantitatif serta metode analisis data yang terdiri dari uji asumsi klasik yang terdiri dari uji normalitas, dan uji heteroskedastisitas, uji regresi linear berganda, uji hipotesis yang terdiri dari uji t dan uji f dan uji koefisien determinasi $\left(\mathrm{R}^{2}\right)$. Pengerjaan metode analisis data menggunakan bantuan SPSS 25 For windows. Penelitian ini menyimpulkan bahwa variabel promosi dan harga berpengaruh positif dan signifikan terhadap keputusan pembelian pada PT. Wahana Chemindo Jaya Medan. Hasil ini dapat dilihat berdasrkan pengujian koefisien determinasi yang menghasilkan nilai $R$ square sebesar 0,787 . Hal ini menunjukkan bahwa promosi dan harga mampu mempengaruhi keputusan pembelian pelanggan PT. Wahana Chemindo Jaya Medan sebesar 78,7\%.
\end{abstract}

Kata Kunci: Promosi; Harga; Keputusan Pembelian 


\section{Pendahuluan}

Perkembangan dunia saat ini berjalan dengan pesat, yang menciptakan suatu persaingan yang semakin ketat. Hal ini yang menuntut produsen untuk lebih peka, kritis dan kreatif terhadap perubahan yang ada, baik politik, sosial budaya, dan ekonomi. Syarat yang harus dipenuhi oleh suatu perusahaan agar dapat mencapai sukses dalam persaingan adalah berusaha mencapai tujuan untuk menciptakan dan mempertahankan pelanggan. Agar tujuan tersebut tercapai, maka setiap perusahaan harus berupaya menghasilkan dan menyampaikan barang dan jasa yang diinginkan konsumen dengan harga yang pantas. Dengan demikian, setiap perusahaan harus mampu memahami kelangsungan hidup perusahaan tersebut sebagai organisasi yang berusaha memenuhi kebutuhan dan keinginan para konsumen sangat tergantung pada perilaku konsumennya.

Dalam melakukan pemasaran yang baik, produsen terlebih dahulu harus mengetahui apa yang menjadi kebutuhan dan keinginan konsumen, sehingga produk yang ditawarkan akan sesuai dengan permintaan konsumen. Adanya pasar bebas yang mengakibatkan dunia perdagangan membuat persaingan usaha semakin ketat. Perusahaan yang tidak mampu bersaing pada akhirnya akan dikalahkan oleh pesaingnya. Untuk mencapai tujuan tersebut maka perushaaan memerlukan berbagai usaha agar tujuan yang telah di rencanakan tercapai.

Pada dasarnya kebutuhan dan keinginan konsumen selalu berubah bahkan meningkat dari waktu ke waktu, sehingga perusahaan perlu melakukan riset pemasaran dalam upaya untuk mengetahui produk apa yang sebenarnya dibutuhkan dan diinginkan oleh konsumen. Konsumen dalam mengambil keputusan untuk membeli suatu produk yang ditawarkan banyak dipengaruhi oleh persepsi mereka terhadap harga produk, promosi, tempat (bauran pemasaran) yang telah diterapkan oleh perusahaan selama ini. Promosi adalah suatu faktor yang penting dalam mewujudkan tujuan penjualan di dalam suatu perusahaan. Salah satu faktor yang berpengaruh terhadap keputusan pembelian adalah promosi.. Dengan promosi perusahaan dapat mengkomunikasikan produk dapat diketahui oleh konsumen dan bisa tertarik untuk mencoba dan kemudian akan mengambil keputusan untuk membeli suatu produk tersebut. Menurut Swasta dan Irawan dalam(Vier, 2019) promosi pada hakekatnya adalah suatu bentuk komunikasi pemasaran yang bertujuan untuk mendorong permintaan, yang dimaksud dengan komunikasi pemasaran adalah kegiatan pemasaran yang berusaha menyebarkan informasi, mempengaruhi dan mengingatkan pasar sasaran terhadap perusahaan dan produknya agar bersedia menerima, membeli, dan loyal terhadap produk atau jasa yang ditawarkan oleh perusahaan yang bersangkutan. Jadi promosi merupakan aspek penting dalam manajemen pemasaran karena promosi dapat membuat konsumen yang semula tidak tertarik pada suatu produk dapat berubah pikiran dan menjadi tertarik untuk membeli produk tersebut pada produk tersebut.

Selain promosi, faktor yang mempengaruhi keputusan pembelian adalah harga. Harga memiliki peranan yang sangat penting dalam mempengaruhi konsumen untuk meningkatkan minat beli konsumen. Menurut Sumarwan dalam (Roy, 2019) harga adalah unsur yang dipergunakan untuk bauran pemasaran yang bisa dikontrol oleh institusi. Ketika konsumen memiliki informasi yang akurat mengenai suatu produk yang satu dengan produk sejenisnya dan menentukan produk mana yang dapat memberi kepuasan lebih.

Hubungan antara harga dengan keputusan pembelian adalah harga dapat mempengaruhi keputusan konsumen dalam melakukan pembelian, semakin tinggi harga maka keputusan pembelian semakin rendah, sebaliknya jika harga rendah keputusan pembelian semakin tinggi Kotler dan Amrstrong dalam (Vier, 2019), oleh karena itu para 
pengusaha harus teliti dalam menetapkan harga produknya ke pasar agar produk tersebut sukses dipasar. PT. Wahana Chemindo Jaya bergerak dalam bidang industry naffcool, bahan baku, low aromatic, paraffin, minarex, soda ash. Dengan adanya persaingan yang sangat ketat dalam industri kimia, perusahaan harus menetapkan strategi yang tepat sehingga dapat mencapai hasil yang diharapkan. Usaha yang dilakukan PT. Wahana Chemindo Jaya dalam menjual produknya melalui promosi diantaranya dengan melalui google business, sehingga ketika konsumen mencari bahan-bahan kimia seperti Minarex H, LILIN, RPO, dan lainnya di google maka nama perusahaan ini langsung muncul sehingga sangat memudahkan konsumen untuk mencari bahan-bahan kimia yang dijual oleh perusahan tersebut.

Berdasarkan wawancara peneliti dengan karyawan perusahaan diketahui bahwa promosi yang dilakukan hanya untuk kalangan yang mengerti dengan internet dalam mencari bahan-bahan kimia tersebut tetapi untuk kalangan masyarakat yang belum mengetahui tentang google business ini tidak mengetahui keberadaan atau pun apa saja yang dijual di perusahaan tersebut karena perusahaan tersebut tidak memasarkan secara langsung sehingga promosi yang dilakukan pihak perusahaan tersebut masih kurang tepat dan perlu adanya pembaharuan/penambahan seperti dengan melakukan pemasaran langsung atau dengan majalah, brosur dan lain-lainnya. Bauran pemasaran seperti harga perusahaan ini mengikuti harga minyak dunia atau juga mengikuti harga yang ditawarkan oleh perusahaan pertamina. Sehingga ketika harga minyak dunia naik maka penjualan minyak di perusahaan ini akan naik, dan sebaliknya. Sehingga penjualan pada perusahaan ini tidak stabil.

Berdasarkan wawancara peneliti dengan karyawan perusahaan diketahui bahwa bahan-bahan kimia (minyak mentah) yang diproduksi oleh perusahan PT. Wahana chemindo Jaya Medan adalah racikan dari bahan-bahan kimia (minyak mentah) oleh Pertamina, sehingga apabila perusahaan tersebut mengikuti harga minyak dunia atau juga mengikuti harga yang ditawarkan oleh perusahan maka konsumen akan lebih memilih pertamina karena pertamina sudah perusahaan yang dikenal sejak lama, sedangkan perusahaan ini masih baru dan belum terlalu dikenal oleh masyarakat maupun perusahan lainnya. Sehingga penjualan pada perusahaan ini mengalami ketidakstabilan. Berikut ini disajikan data penjualan pada PT. Wahana Chemindo Jaya selama 1 tahun terakhir.

Tabel 1. Data Penjualan Bahan-Bahan Kimia Pada Tahun 2020

(Periode Januari-Juni 2020)

\begin{tabular}{|c|c|c|c|c|c|c|}
\hline \multirow{2}{*}{$\begin{array}{l}\text { Nama } \\
\text { barang }\end{array}$} & \multicolumn{6}{|c|}{ Jumlah yang terjual } \\
\hline & Januari & Februari & Maret & April & Mei & Juni \\
\hline $\begin{array}{l}\text { Minarex h } \\
\text { (drum) }\end{array}$ & 20 drun & 30 drum & 10 drum & 15 drum & 5 drum & 13 drum \\
\hline Lilin & 100 sack & 100 sack & 30 sack & 50 sack & 20 sack & 40 sack \\
\hline Rpo & 2 drum & 3 drum & 1 drum & 2 drum & 1 drum & 1 drum \\
\hline Minarex 1 & 2 drum & 3 drum & 1 drum & 2 drum & 1 drum & 1 drum \\
\hline Paraffin oil & 19 drum & 20 drum & 5 drum & 10 drum & 3 drum & 8 drum \\
\hline Minarex 40 & 1 drum & 1 drum & 1 drum & 1 drum & - & 1 drum \\
\hline SMT & 1 drum & 2 drum & 1 drum & 1 drum & - & 1 drum \\
\hline Sodium & 1 Drum & 1 drum & 1 drum & 1 drum & 1 drum & 1 drum \\
\hline Therpentine & 6 drum & 8 drum & 2 drum & 3 drum & 2 drum & 2 drum \\
\hline Total & $\begin{array}{l}52 \text { drum } \\
/ 100 \text { sack } \\
=214 \text { juta }\end{array}$ & $\begin{array}{l}69 \text { drum } \\
/ 100 \text { sack } \\
=306 \text { juta }\end{array}$ & $\begin{array}{l}22 \text { drum } \\
150 \text { sack } \\
=93 \text { juta }\end{array}$ & $\begin{array}{l}35 \text { drum } \\
150 \text { sack } \\
=137 \text { juta }\end{array}$ & $\begin{array}{l}12 \text { drum } \\
/ 20 \text { sack } \\
=42 \text { juta }\end{array}$ & $\begin{array}{l}28 \text { drum } \\
140 \text { sack } \\
=128 \text { juta }\end{array}$ \\
\hline
\end{tabular}


Tabel 2. Data Penjualan Bahan-Bahan Kimia Pada Tahun 2020

(Periode Juli - Desember 2020)

\begin{tabular}{|l|l|l|l|l|l|l|}
\hline \multirow{2}{*}{$\begin{array}{c}\text { Nama } \\
\text { Barang }\end{array}$} & \multicolumn{1}{|c|}{ Juli } & Agustus & September & Oktober & November & Desember \\
\cline { 2 - 7 } $\begin{array}{l}\text { Minarex h } \\
\text { drum) }\end{array}$ & 25 drum & 40 drum & 15 drum & 20 drum & 30 drum & 13 drum \\
\hline Lilin & 100 sack & 100 sack & 50 sack & 50 sack & 100 sack & 30 sack \\
\hline Rpo & 2 drum & 4 drum & 2 drum & 2 drum & 4 drum & 1 drum \\
\hline Minarex 1 & 2 drum & 4 drum & 2 drum & 2 drum & 4 drum & 1 drum \\
\hline Paraffin oil & 15 drum & 23 drum & 10 drum & 10 drum & 20 drum & 5 drum \\
\hline Minarex 40 & 1 drum & 2 drum & 1 drum & 1 drum & 2 drum & 1 drum \\
\hline SMT & 1 drum & 1 drum & 1 drum & 1 drum & 1 drum & 1 drum \\
\hline Sodium & 1 drum & 3 drum & 1 drum & 1 drum & 3 drum & 1 drum \\
\hline Therpentine & 4 drum & 10 drum & 3 drum & 3 drum & 8 drum & 2 drum \\
\hline Total & $\begin{array}{l}51 \text { drum } \\
/ 100 \text { sack } \\
=258 \text { juta }\end{array}$ & $\begin{array}{l}87 \text { drum } \\
100 \text { sack } \\
=400 \text { juta }\end{array}$ & $\begin{array}{l}35 \text { drum } \\
/ 50 \text { sack } \\
=137 \text { juta }\end{array}$ & $\begin{array}{l}40 \text { drum } \\
/ 50 \text { sack } \\
=158 \text { juta }\end{array}$ & $\begin{array}{l}72 \text { drum } \\
100 \text { sack } \\
=354 \text { juta }\end{array}$ & $\begin{array}{l}25 \text { drum } \\
/ 50 \text { sack } \\
=96 \text { juta }\end{array}$ \\
\hline
\end{tabular}

Sumber: data primer yang diperoleh dari PT.Wahana Chemindo jaya.

Pada tabel diatas menjelaskan bahwa volume penjualan bahan-bahan kimia (minyak mentah) PT. Wahana Chemindo Jaya mengalami penjualan yang fluktuatif, dimana penjualan hanya pada bulan-bulan tertentu saja yang jumlah penjualannya cukup besar, yaitu pada bulan Januari, February, Agustus dan Nopember, sedangkan pada bulanbuan lainnya omzet penjualan hanya setengah bahkan kurang dari penjualan pada bulanbulan tersebut sehingga dapat dikatakan pembelian minyak mentah atau bahan-bahan kimia pada PT. Wahana Chemindo Jaya cenderung tidak stabil. Penurunan penjualan minyak mentah tersebut diperkirakan akan terus terjadi apabila tidak mengambil strategi untuk mengantisipasinya. Oleh karena itu, diperlukan pemahaman yang serius dari pihak manajemen terhadap faktor-faktor yang mempengaruhi pertumbuhan volume penjualan untuk terus meningkatkan dalam rangka mempertahankan dan meningkatkan keputusan pembelian konsumen.

\section{Metode}

Penelitian ini dilakukan di PT. Wahana Chemindo Jaya, Jl. Karantina II No.64B, Kec. Medan Timur, Kota Medan, Sumatera Utara, mulai pada bulan Maret s/d Juli tahun 2021. Populasi dalam penelitian ini adalah jumlah pelanggan PT. Wahana Chemindo Jaya Kota Medan. Berdasarkan data yang didapatkan melalui survei ke PT. Wahana Chemindo Jaya JL. Karantina Medan, sebanyak 182 responden dengan sampel yang berjumlah sebanyak 65 reponden dengan rumus slovin dengan Teknik pengambilan sampel yang digunakan non probability sampling dengan jenis accidental sampling. Accidental sampling, yaitu Teknik penentuan sampel berdasarkan kebetulan, yaitu siapa saja yang secara kebetulan ditemui oleh peneliti dan memiliki kriteria yang sesuai dijadikan sebagai sampel. Teknik pengumpulan data dalam penelitian ini adalah kuisioner online. Kuisioner adalah salah satu metode penelitian yang terdiri dari sekumpulan pertanyaan atau jenis petunjuk lainnya yang bertujuan untuk mengmpulkan informasi dari seorang responden. Kuisioner penelitian biasanya merupakan campuran dari pernyataan tertutup dan pernyataan terbuka. Uji validitas suatu instrument (dalam angket) dilakukukan dengan mengukur korelasi antara variabel atau item dengan skor total variabel menggunakan rumus teknik kolerasi pearson product moment correlation coefficient $(r)$. Pengujian 
reliabilitas digunakan untuk mengukur konsistensi jawaban responden, kriteria pengujian dilakukan dengan menggunakan pengujian Cronbach alpha. Untuk mengetahui instrument reliabel atau tidak dengan cara mengkonsultasikan $r$ alpha Cronbach dengan 0,6 .

\section{Hasil dan Pembahasan}

\section{Uji Validitas}

Kriteria pengujian:

Rhitung $>$ Rtabel $=$ valid, dan diperoleh $r$ tabel sebesar 0,258. Semua pernyataan dinyatakan valid karena hasil uji validitas promosi, harga dan keputusan pembelian > 0,258 .

Tabel 3. Uji Reabilitas

\section{Reliability Statistics}

\begin{tabular}{r|r}
$\begin{array}{c}\text { Cronbach's } \\
\text { Alpha }\end{array}$ & N of Items \\
\hline .903 & 22 \\
\hline
\end{tabular}

Berdasarkan hasil uji reablitas pada tabel diatas dengan menggunakan uji statistic Cronbach alpha $(\alpha)$, menunjukkan bahwa semua variabel memiliki Cronbach alpha > 0,60 . Hal tresebut menunjukkan bahwa kuisioner yang digunakan untuk mengukur variabel promosi, harga dan keputusan pembelian tersebut adalah reliabel.

\section{Analisis Deskriftif Responden}

Tabel 4. Responden berdasarkan jensi kelamin

\begin{tabular}{|c|c|c|}
\hline $\begin{array}{c}\text { Jenis } \\
\text { kelamin }\end{array}$ & Jumlah & $\begin{array}{c}\text { Presentase } \\
(\%)\end{array}$ \\
\hline Laki-laki & 30 & 46,15 \\
\hline Perempuan & 35 & 53,85 \\
\hline Total & 65 & 100 \\
\hline
\end{tabular}

Berdasarkan tabel karakteristik responden berdasarkan jenis kelamin menunjukkan bahwa 65 responden yang diteliti, responden berjenis kelamin laki-laki 46,15\% dan responden berjenis kelamin perempuan yaitu 53,85\%. Hal ini menunjukkan bahwa responden perempuan lebih dominan dari pada berjenis kelamin laki-laki dalam penelitian ini.

Tabel 5. Responden Berdasarkan Umur
\begin{tabular}{|c|c|c|}
\hline $\begin{array}{c}\text { Umur } \\
\text { (Tahun) }\end{array}$ & Jumlah & $\begin{array}{c}\text { Presentase } \\
(\%)\end{array}$ \\
\hline $30-35$ & 28 & 43,07 \\
\hline $36-50$ & 37 & 56,93 \\
\hline Total & 65 & 100 \\
\hline
\end{tabular}

Berdasarkan tabel karakteristik responden berdasarkan umur dalam penelitian ini adalah yang berusia 30-35 tahun sebanyak 28 responden dengan presentase $43,07 \%$, responden yang berusia 36-50 tahun sebanyak 37 responden dengan presntase 56,93\%. Berdasarkan data pada tabel 4.2 dapat disimpulkan bahwa mayoritas pelanggan PT. Wahana Chemindo Jaya Medan berusia 36-50 tahun. 


\section{Uji Normalitas}

a. Uji Kolomogrov-Smirnov

Tabel 6. Uji Kolomogrov-Smirnov

One-Sample Kolmogorov-Smirnov Test

\begin{tabular}{|c|c|c|}
\hline & & $\begin{array}{l}\text { Unstandardic } \\
\text { ed Residual }\end{array}$ \\
\hline \multicolumn{2}{|l|}{$\mathrm{N}$} & 65 \\
\hline \multirow[t]{2}{*}{ Normal Parameters ${ }^{a . b}$} & Mean & 0000000 \\
\hline & Std. Deviaton & 1.26588624 \\
\hline \multirow[t]{3}{*}{ Most Extreme Differences } & Absolute & .088 \\
\hline & Positive & .054 \\
\hline & Negative & .088 \\
\hline \multicolumn{2}{|l|}{ Test Statistic. } & .088 \\
\hline \multicolumn{2}{|l|}{ Asymg Sig (2tailed) } & $200^{c, d}$ \\
\hline
\end{tabular}

Berdasarkan hasil pengolahan data pada tabel diatas diperoleh besarnya Kolmogorov-smirnov adalah 0,200. Nilai signifkansi lebih besar dari 0,05 maka dapat dikatakan bahwa nilai residual berdistribusi normal.

b. Grafik Histogram

Pada grafik histogram diatas, dapat dilihat bahwa grafik histogram berbentuk lonceng terbalik, tidak miring ke kiri dan ke kanan. Oleh karena itu data dikatakan berdistribusi normal. Seperti terlihat pada grafik di bawah ini:

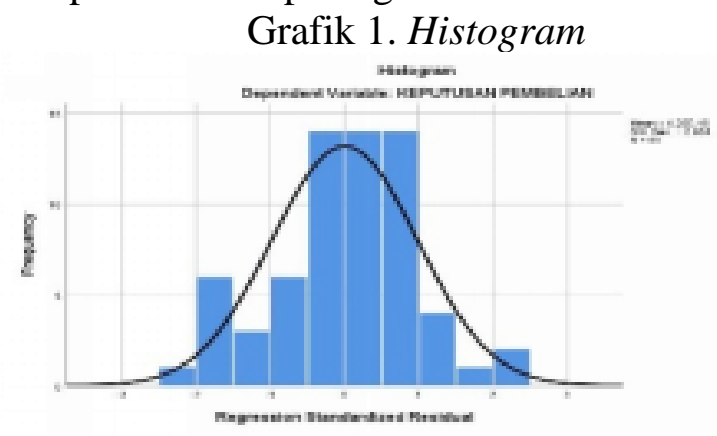

Berdasarkan gambar histogram diatas dapat dilihat bahwa data tersebut berdistibusi normal. Hal ini ditunjukkan oleh distribusi data pada grafik histogram tersebut dengan bentuk lonceng terbalik dan tidak miring ke keri dan kekanan.

c. Grafik P-P plot

Pendekatan ini dilakukan dengan melihat data titik-titik yang tersebar disepanjang garis diagonal mengikuti garis diagonal, maka data berdistribusi normal.

\section{Grafik 2. P-P plot}

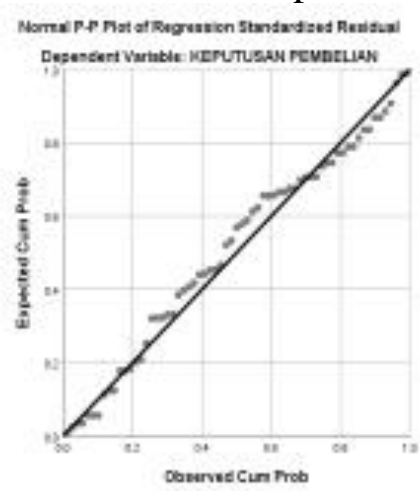

Grafik p-plot diatas menunjukkan bahwa gambar data menunjukkan data menyebar di sekitar garis diagonal dan mengikuti arah garis diagonal. Oleh karen itu, data dapat dikatakan berdistribusi normal. 


\section{Uji Multikolinieritas}

Berdasarkan hasil pengolahan SPSS, diketahui bahwa nilai tolerance pada variabel Promosi $\left(\mathrm{X}_{1}\right)$ dan Harga $\left(\mathrm{X}_{2}\right)$ sebesar 0,932 > 0,10 sedangkan nilai VIF untuk variabel Promosi $\left(\mathrm{X}_{1}\right)$ dan Harga $\left(\mathrm{X}_{2}\right)$ sebesar $1.073<10$. Mengacu pada dasar pengambilan keputusan, dapat disimpulkan bahwa tidak terjadi multikolinearitas dal model regresi.

\section{Uji Heteroskedastisitas}

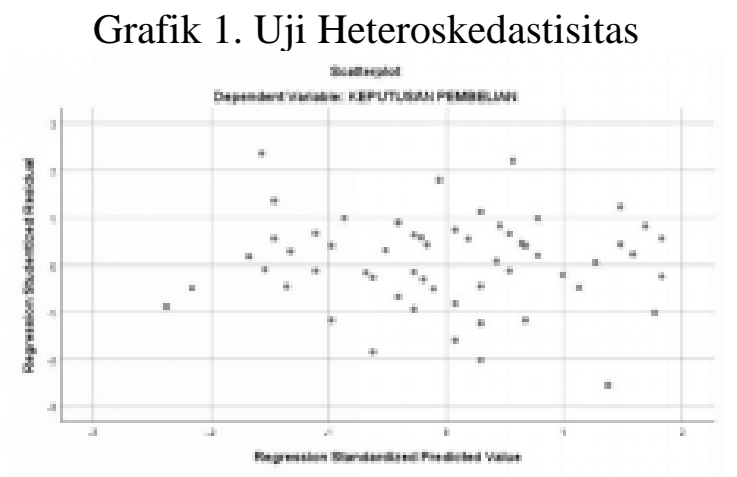

Berdasarkan grafik scatterplot yang pada gambar diatas dapat dilihat titik-titik menyebar secara acak tidak membentuk pola tertentu yang jelas serta tersebar baik diatas maupun dibawah angka nol pada sumbu Y. Hal ini menunjukkan tidak terhadi heteroskedastisitas pada model regresi, sehingga model regresi dapat dipakai untuk memprediksikan keputusan pembelian berdasarkan masukan variabel independennya.

\section{Hasil Analisis Regresi Berganda}

$$
\mathrm{Y}=4,146+0,260 \mathrm{X} 1+0,853 \mathrm{X} 2
$$

Berdasarkan persamaan analisis regresi linear berganda ini dapat diartikan sebagai berikut:

a. Nilai kosntanta sebesar 4,146, apabila variabel inovasi dan kualitas produk dianggap nol, maka keputusan pembelian produk bahan kimia pada PT.Wahana Chemindo Jaya Medan adalah sebesar 4,146atau 41,46 \%.

b. Nilai koefisien promosi $\left(\mathrm{X}_{1}\right)$ sebesar 0,260 menyatakan bahwa setiap kenaikan promosi yang semakin baik maka keputusan pembelian (Y) akan mengalami kenaikan sebesar 0,260 atau $26,0 \%$.

c. Nilai koefisien harga $\left(\mathrm{X}_{2}\right)$ sebesar 0,853 menyatakan bahwa setiap kenaikan kualitas produk makin baik maka keputusan pembelian (Y) akan mengalami kenaikan sebesar 0,853 atau $85,3 \%$.

\section{Uji Parsial (Uji T)}

Berdasarkan hasil pengolahan SPSS dapat dilihat pengaruh dari setiap variabel secara parsial adalah sebagai berikut:

a. Berdasarkan pengujian software statistic 25 , diperoleh hasil pengujian berkaitan dengan teori variabel promosi berpengaruh positif dan signifikan terhadap keputusan pembelian. Hal ini dapat dilihat dari nilai $t_{\text {hitung }}$ sebesar $(3.014)>t_{\text {tabel }}$ (1.66980) dan signifikan variabel promosi yaitu sig sebesar 0,004 < 0,05 maka H1 diterima. Demikian diambil kesimpulan bahwa varibael Promosi (X1) berpengaruh signifikam terhadap variabel keputusan pembelian (Y).

b. Berdasarkan pengujian software statistic 25, diperoleh hasil pengujian berkaitan dengan teori variabel harga berpengaruh positif dan signifikan terhadap keputusan pembelian. Hal ini dapat dilihat dari nilai $t_{\text {hitung }}$ sebesar $(15,111)>t_{\text {tabel }}(1.66980)$ 
dan signifikan variabel Harga yaitu sig sebesar 0,000 < 0,05 maka $\mathrm{H} 2$ diterima. Demikian diambil kesimpulan bahwa varibael harga (X2) berpengaruh signifikan terhadap variabel keputusan pembelian (Y).

\section{Uji Simultan (Uji F)}

Dari hasil pengolahan SPSS dapat diketahui bahwa $f_{\text {hitung }}>f_{\text {tabel }}$ yaitu 114,619 > 2,39 dan nilai signifikan $0,000<0,05$. Hal ini berarti variabel promosi dan harga secara bersama sama berpengaruh positif san signifikan terhadap keputusan pembelian produk bahan kimia pada PT.Wahana Chemindo Jaya Medan.

\section{Uji Koefisien Determinasi $\left(\mathbf{R}^{2}\right)$}

Tabel 7. Uji Koefisien Determinasi $\left(\mathrm{R}^{2}\right)$

\begin{tabular}{|c|c|c|c|c|}
\hline \multirow[b]{2}{*}{ Modei } & \multicolumn{3}{|c|}{ Model Summary' } & \multirow[b]{2}{*}{$\begin{array}{l}\text { S4d. Error of } \\
\text { the Estimate }\end{array}$} \\
\hline & $R$ & R Square & $\begin{array}{c}\text { Adfusted R } \\
\text { Square }\end{array}$ & \\
\hline 1 & $887^{3}$ & 787 & 780 & 1.286 \\
\hline
\end{tabular}

Berdasarkan hasil SPSS diatas dapat dilihat bahwa nilai R sebesar 0,887. Dimana nilai koefisien ini menunjukkan hubungan antara promosi dan harga terhadap keputusan pembelian kuat karena jika nilai R semakin emndekati satu maka semakin baik pula model tersebut digunakan. Nilai R square sebesar 0,787 berarti $78,7 \%$ menunjukkan bahwa keputusan pembelian dapat dijelaskan oleh variabel promosi dan harga sedangkan sisanya 21,3\% dapat dijelaskan oleh variabel lain yang tidak diteliti oleh penelitian ini seperti variabel inovasi, kualitas produk dan variabel lainnya.

a. Pengaruh Promosi Terhadap Keputusan Pembelian

$\mathrm{H} 1=$ Hasil analisis penelitian ini menunjukkan bahwa promosi memiliki pengaruh positif dan signifikan terhadap keputusan pembelian pada PT.Wahana Chemindo Jaya Medan. Hal tersebut dapat dilihat dari hasil pengujian yang dilakukan secara parsial (uji-t) dengan menggunakan program SPSS dimana nilai $t_{\text {hitung }}(3,014)>t_{\text {tabel }}(1,66980)$ dan nilai signifikan $0,004<0,05$.

b. Pengaruh Harga Terhadap Keputusan Pembelian

$\mathrm{H} 2=$ Hasil analisis penelitian ini menunjukkan bahwa harga memiliki pengaruh positif dan signifikan terhadap keputusan pembelian pada PT.Wahana Chemindo Jaya Medan. Hal tersebut dapat dilihat dari hasil pengujian yang dilakukan secara parsial (uji-t) dengan menggunakan program SPSS dimana nilai terlihat $t_{\text {hitung }}(15,111)>t_{\text {tabel }}$ $(1,66980)$ dan nilai signifikan $0,000<0,05$.

c. Pengaruh Promosi (X1) dan Harga(X2) Terhadap Keputusan Pembelian.

$\mathrm{H} 3=$ Berdasarkan hasil penelitian secara simultan promosi dan harga berpengaruh positif dan signifikan terhadap keputusan pembelian. Hal ini ditunjukkan oleh hasil nilai $f_{\text {hitung }}$ pada promosi dan harga yang lebih besar dari f tabel $(114,619>2,39)$, hal

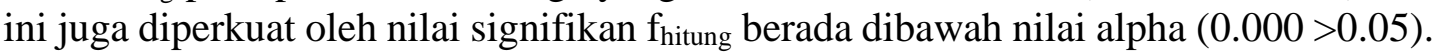

\section{Kesimpulan}

1. Pengaruh promosi terhadap keputusan pembelian konsumen pada PT.Wahana Chemindo Jaya Medan berpengaruh positif sebesar 3,014 dan nilai siginifikan sebesar 0,004 . 
2. Pengaruh harga terhadap keputusan pembelian konsumen pada PT.Wahana Chemindo Jaya Medan berpengaruh positif sebesar 15,111 dan nilai siginifikan sebesar 0,000.

3. Pengaruh promosi dan harga terhadap keputusan pembelian konsumen pada PT.Wahana Chemindo Jaya Medan berpengaruh positif sebesar 114,619 dan nilai siginifikan sebesar 0,000 .

\section{Daftar Pustaka}

Armayani, A. (2019). Peran Brand Image Memediasi Promosi Dan Harga Terhadap Keputusan Pembelian Smartphone Samsung Di Kota Denpasar. Ejmunud: Jurnal Manajemen. 8(8),5222-5239.

Dewi. (2017). Pengaruh Harga Dan Promosi Terhadap Keputusan Pembelian Sampo Pantene Dikota Malang. Jurnal Manajemen. Vol.5. No. 1

Fathimah, F. (2015). Pengaruh Bauran Pemasaran Terhadap Kepuasan Konsumen Air Mineral Asa Di Samarinda. EJurnalAdbisnis: Jurnal Manajemen. 1(4),340-350.

Irawan, R. dkk. (2019). Pengaruh Promosi, Prouk Dan Harga Terhadap Keputusan Pembelian Produk Onderdil Astra Honda Motor (AHM) Pada UD. Rasa Motor Di Lumajang. Jurnal Manajemen. Vol. 2. No. 1

Kurniawan, D. dkk. (2015). Pengaruh Promosi Dan Harga Terhadap Keputusan Pembelian Rokok Djarum Super Dengan Kepuasan Konsumen Sebagai Variabel Moderasi. Jurnal Ekonomi dan Kewirausahaan. 15(3), 354-366.

Loindong, S. (2017). Pengaruh Kualitas Produk, Harga Dan Promosi Terhadap Keputusan Pembelian Mobil Nissan X-Trail Pada PT. Wahana Wirawan Manado. EMBA: Jurnal Riset Ekonomi, Manajemen, Bisnis dan Akuntansi.5(2),2221-2229.

Pasaribu, R. F. A., Sianipar, I. L., Siagian, Y. F., \& Sartika, V. (2019). Pengaruh Promosi Dan Harga Terhadap Keputusan Pembelian Produk Soyjoy Pt. Amerta Indah Otsuka Kota Medan. Jurnal Manajemen, 5(1),45-52.

Roy, R. (2019). Pengaruh promosi, harga dan inovasi terhadap minat beli mobil ayla di PT.Capella Malang. Mutiara Manajemen, 5(1),21-29.

Sholilat, A. (2018). Pengaruh Promosi Penjualan Dan Kualitas Pelayanan Terhadap Keputusan Pembelian Di Krema Koffe. JOMFSIP : Jurnal Online Mahasiswa Fakultlas Sosial Ilmu Politik. 5(1),1-15.

Sugiyono. (2016). Metode Penelitian Kuantitatif, Kualitatif dan R\&D. Bandung: Alfabeta Suprihadi, H. (2016). Pengaruh Diskon Harga, Merek Produk Dan Layanan Pelanggan Terhadap Keputusan Pembelian Garmen. Jurnal Ilmu \& Riset Manajemen. 2(8),119.

Walangitan, O. (2019). Pengaruh Promosi Dan Harga Terhadap Keputusan PadaPembelian PT. Shopee International Indonesia Di Kota Manado. Jurnal Administrasi Bisnis.9(3), 35-43.

Wibowo, S.F. (2015). Pengaruh Iklan Televisi Dan Harga Terhadap Keputusan Pembelian Sabun Lux 9 survei Pada Pengunjung Mega Bekasi Hypermall). JRMSI: Jurnal Riset Manajemen Sains Indonesia. 3(1),1-15.

Wijayanti. (2015). Analisis Yang Mempengaruhi Keputusan Pembelian Konsumen Terhadap Pembersih Wajah Ovale. JAM: Jurnal Aplikasi Manajemen. 6(2),138154. 